\title{
ESTIMATION OF RISK FACTORS OF EARLY POSTOPERATIVE MORTALITY IN ELDERLY PATIENTS WHO ARE SUBJECTED TO GASTRIC SURGICAL PROCEDURES
}

\author{
Ivan Pešić ${ }^{1,2}$, Milica Nestorović ${ }^{1,2}$, Vanja Pecić ${ }^{3}$, Milan Radojković ${ }^{1,2}$, Lidija Đorđević ${ }^{4}$, Miodrag Đorđević ${ }^{4}$, \\ Toplica Bojić ${ }^{4}$ \\ ${ }^{1}$ Clinic for Digestive Surgery, Clinical Center Niš, Niš, Serbia \\ ${ }^{2}$ Faculty of Medicine, University of Niš, Niš, Serbia \\ ${ }^{3}$ Center for Minimally Invasive Surgery, Clinical Center Niš, Niš, Serbia \\ ${ }^{4}$ Clinic for Endocrine and Breast Surgery, Clinical Center Niš, Niš, Serbia
}

\begin{abstract}
The use of screening programms in elderly population (age $\geq 65$ years) comprises an increasing proportion of patients undergoing emergency general surgery (EGS) procedures nowadays. The aim was to determine the intra-hospital mortality rate in elderly patients undergoing gastric surgical procedures. 108 elderly patients $(\geq 65$ years old) were examined, divided into two groups: deceased and surviving surgical patients, treated for diseases (benign and malignant) of the stomach. The patients were divided into four age groups and five ASA groups, taking into account the presence of chronic diseases, the values of some laboratory parameters, administered transfusion and the occurrence of surgical complications during hospitalization. The mortality rate among elderly patients was $28.7 \%$. The significant risk factors for mortality were: emergency surgery $(p<0.001)$, bleeding gastric ulcer operations $(p=0.042)$, lung $(p=0.003)$, kidney $(p<$ $0.001)$, heart ( $p=0.025)$ diseases, ASA score of 4 or higher $(p<0.001)$, serum levels (higher after two times measurement) of creatinine, haemoglobin, CRP, PCT and glycemia $(p<0.001)$. In order to improve medical treatment, the determination of independent validated risk indicators for mortality in elderly patients might lead to developing a dedicated scoring system.
\end{abstract}

Key words: elderly, gastric surgery, mortality.

\section{Introduction}

In people aged 65 or older, the patient's risk of requiring surgical procedures is three times higher than in the younger population, especially in the case of emergency conditions [1]. Surgeons are still generally reluctant to treat elderly patients, considering them more sensitive to surgical treatments, having lower physiological reserves inside themselves, as well as more concealed diseases $[1,2]$. The aim of the research was to determine the overall rate of early postoperative mortality of elderly patients undergoing gastric surgical interventions, with an overview of the impact of the ASA score, malignant diseases, septic conditions, associated chronic diseases, surgical complications and some laboratory parameters to the occurrence of the mentioned.

\section{Materials and Methods}

The study includes the examination of 108 elderly patients ( $\geq 65$ years of age) in the period from $1^{\text {st }}$ January 2013 to $31^{\text {st }}$ December 2014 at the Clinic for General

Correspondence to: Ivan Pešić, M.D., Ph.D.

Faculty of Medicine, 81 Zoran Đinđić Blvd., 18000 Niš, Serbia

Phone: +381606622964

E-mail: sicpeni1977@yahoo.com

Received May $7^{\text {th }}, 2019$
Surgery of the Clinical Center in Nis, divided into two groups: deceased and surviving surgical patients. Patients were surgically treated for diseases (benign and malignant) of the stomach, with attention to the type of operation (emergency, elective), associated chronic diseases (heart and kidney diseases, pulmonary function disorder, neurological diseases of the CNS, diabetes), number of transmitted red blood cell (RBC) concentrates units and frozen fresh plasma (FFP) units. Four age groups of patients were examined: the $1^{\text {st }}$ group of patients aged 65 to $69 ; 2^{\text {nd }}$ group of patients from 70 to 75 years of age; $3^{\text {rd }}$ group of patients between 76 and $80 ; 4^{\text {th }}$ group of patients aged over 80 . In the study, patients were also included in the ASA classification, and divided into five categories [3]. The study also included monitoring some laboratory parameters (serum creatinine, serum albumin, total serum proteins, erythrocyte values, leukocytes, serum hemoglobin, serum sodium and potassium values, C-reactive protein-CRP, procalcitonin-PCT, glycaemia) with their measurement on two occasions during patient hospitalization: before the surgery itself and just before the end of the clinical treatment or before the fatal outcome. The tables show the average values of the tested parameters. Following surgical complications were observed: laparotomy dehiscence, dehiscence of the primarily performed gastrointestinal anastomosis, postoperative bleeding. The data 
are presented in the form of an arithmetic mean and a standard deviation, or in the form of absolute and relative numbers. Frequency comparisons were done with the Chi-squared test. The comparison of the continuous variables was done with the Mann-Whitney test. The hypothesis was tested with a significance threshold of $\mathrm{p}<0.05$. The data analysis was performed with the SPSS 16.0 software package.

\section{Results}

In this study of 108 patients with gastric surgical diseases, there were $77(71.30 \%)$ surviving and $31(28.70 \%)$ deceased patients. None of the age groups represented significant risk factors in early postoperative mortality $(\mathrm{p}=0.922)$. Emergency surgical procedures, ASA score 4 or higher were statistically significantly more common in group of deceased gastric surgical patients ( $p<0.001)$. Malignant diseases were more common in group of surviving gastric surgical patients $(55.80 \%$ vs. $48.40 \%)$.
Bleeding / perforation of gastric ulcer or gastric tumor were statistically significantly more common in deceased gastric surgical patients $(\mathrm{p}=0.024 ; \mathrm{p}=0.027$ ). Respiratory disorders and renal diseases were statistically significantly more common in deceased gastric surgical patients $(\mathrm{p}=0.003 ; \mathrm{p}<0.001)$. Heart diseases were more common in surviving gastric surgical patients $(p=0,025)$. The average number of transmitted FFP units was statistically significantly more common in surviving gastric surgical patients $(\mathrm{p}=0.005)$ (Table 1$)$. The bleeding gastric ulcer surgical operations were more common in deceased gastric surgical patients regarding to surviving patients ( $25.80 \%$ vs $10,40 \%, p=0.042)$ (Table 2$)$. There were statistical difference referring to higher serum concentration of the following values in deceased gastric surgical patients: serum creatinine, hemoglobin, erythrocyte count, leukocyte count, CRP, PCT and glycaemia $(\mathrm{p}<0.001)$ (Table 3). Gastro-intestinal anastomosis dehiscence was determined in 5 deceased surgical gastric patients (16.10\%) (Fisher's test: $\mathrm{p}=0.002$ ).

Table 1 Risk factors of fatal outcome of the examined population

\begin{tabular}{|c|c|c|c|c|c|c|}
\hline \multirow{2}{*}{$\begin{array}{l}\text { Risk factors } \\
\text { Pat. characteristics (age) }\end{array}$} & \multicolumn{2}{|c|}{$\begin{array}{c}\text { Surviving } \\
\mathrm{N}=77(71.30 \%)\end{array}$} & \multicolumn{2}{|c|}{$\begin{array}{c}\text { Deceased } \\
\mathrm{N}=31(28.70 \%)\end{array}$} & \multirow[t]{2}{*}{$\chi^{2}$} & \multirow[t]{2}{*}{$\mathrm{p}$} \\
\hline & & & & & & \\
\hline 65-69 year & 21 & $(27.30 \%)$ & 7 & $(22.60 \%)$ & 0.488 & 0.922 \\
\hline 70-74 year & & $(22.10 \%)$ & 7 & $(22.60 \%)$ & & \\
\hline 75-79 year & 18 & $(23.40 \%)$ & 9 & $(29.00 \%)$ & & \\
\hline$<80$ year & 21 & $(27.30 \%)$ & 8 & $(25.80 \%)$ & & \\
\hline \multicolumn{7}{|l|}{ Clinical characteristics } \\
\hline Emergency op. & & $(26.00 \%)$ & 21 & $(67.70 \%) \dagger$ & 16.37 & $<0.001$ \\
\hline Elective op. & 57 & $(74.00 \%)$ & 10 & $(32.30 \%)$ & & \\
\hline Malignant disease & 43 & $(55.80 \%)$ & 15 & $(48.40 \%)$ & 0.240 & 0.624 \\
\hline Benignant disease & 34 & $(44.20 \%)$ & 16 & $(51.60 \%)$ & & \\
\hline Ulcer/tumor bleeding & 9 & $(11.70 \%)$ & 10 & $(32.30 \%)$ & 5.109 & 0.024 \\
\hline Ulcer/tumor perforation & 11 & $(14.30 \%)$ & 11 & $(35.50 \%)$ & 4.885 & 0.027 \\
\hline Respiratory diseases & 6 & $(7.80 \%)$ & 10 & $(32.30 \%)$ & 8.634 & 0.003 \\
\hline Heart diseases & 74 & $(96.10 \%)$ & 25 & $(80.60 \%)$ & 5.039 & 0.025 \\
\hline Kidney diseases & 0 & & 6 & $(19.40 \%)$ & & $<0.001$ \\
\hline Neurological disorders & 11 & $(14.30 \%)$ & 4 & $(12.90 \%)$ & 0.035 & 0.851 \\
\hline Diabetes mellitus & 0 & & 2 & $(6.50 \%)$ & & 0.080 \\
\hline ASA 2 & 66 & $(85.70 \%)$ & 3 & $(9.70 \%)$ & & \\
\hline ASA 3 & 11 & $(14.30 \%)$ & 9 & $(29.00 \%)$ & & \\
\hline ASA 4 & 0 & & 18 & $(58.10 \%)$ & & $<0.001$ \\
\hline ASA 5 & 0 & & 1 & $(3.20 \%)$ & & \\
\hline RBC concentrate units & & $2 \pm 2.23$ & & $74 \pm 4.42$ & 2.2492 & 0.025 \\
\hline FFP units & & $8 \pm 4.31$ & & $39 \pm 2.98$ & 2.824 & 0.005 \\
\hline
\end{tabular}

$\dagger$ - number $(\%), \chi^{2}-$ Chi-squared test

Table 2 Type of operation in the examined population

\begin{tabular}{lrrrrrr}
\hline Type of operation & \multicolumn{2}{c}{ Surviving } & \multicolumn{2}{c}{ Deceased } & $\chi^{2}$ & $\mathrm{p}$ \\
\hline Perf. gastric ulcer oper. & 11 & $(14.30 \%)$ & 6 & $(19.40 \%) \dagger$ & 0.13 & 0.717 \\
Bleeding gastric ulcer oper. & 8 & $(10.40 \%)$ & 8 & $(25.80 \%)$ & 4.12 & 0.042 \\
Gastric malignant tumor oper. & 44 & $(57.10 \%)$ & 15 & $(48.40 \%)$ & 0.38 & 0.540 \\
Gastric benignant tumor oper. & 14 & $(18.20 \%)$ & 2 & $(6.40 \%)$ & 1.57 & 0.210 \\
\hline
\end{tabular}

$\dagger$ - number (\%), $\chi^{2}-$ Chi-squared test, \# Fisher's test 
Table 3 Biochemical parameters of fatal outcome in examined population

\begin{tabular}{|c|c|c|c|c|c|c|c|}
\hline \multirow{2}{*}{$\begin{array}{l}\text { Biochem. } \\
\text { markert }\end{array}$} & \multicolumn{2}{|c|}{ Surviving } & \multicolumn{3}{|c|}{ Deceased } & \multirow[t]{2}{*}{$\mathrm{F} / \mathrm{z}^{*}$} & \multirow[t]{2}{*}{$\mathrm{p}$} \\
\hline & 1st measure. & $2^{\text {nd }}$ measure. & 1st measure. & $2 \mathrm{nd}_{1}$ & neasure. & & \\
\hline Ser. creatinine & $94.17 \pm 56.13$ & $84.74 \pm 44.06$ & $140.13 \pm 70.72$ & 193.39 & \pm 138.13 & 16.696 & $<0.001$ \\
\hline Total proteins & $58.70 \pm 10.80$ & $53.48 \pm 5.53$ & $47.31 \pm 7.62$ & 42.87 & \pm 7.74 & 0.167 & 0.684 \\
\hline Ser. albumin & $33.31 \pm 6.68$ & $29.88 \pm 4.28$ & $24.65 \pm 5.38$ & 23.77 & \pm 4.05 & 5.237 & 0.024 \\
\hline Er. count & $3.76 \pm 0.75$ & $3.48 \pm 0.26$ & $3.02 \pm 0.78$ & 3.44 & \pm 0.72 & 20.924 & $<0.001$ \\
\hline Le. count & $5.92 \pm 1.76$ & $9.69 \pm 1.91$ & $12.25 \pm 6.00$ & 12.99 & \pm 5.46 & 18.288 & $<0.001$ \\
\hline Ser. Hgb & $113.23 \pm 23.50$ & $108.39 \pm 9.39$ & $89.39 \pm 25.22$ & 103.29 & \pm 21.81 & 17.242 & $<0.001$ \\
\hline Serum $\mathrm{Na}$ & $136.51 \pm 4.84$ & $139.73 \pm 3.05$ & $133.90 \pm 5.93$ & 136.97 & \pm 4.79 & 0.019 & 0.889 \\
\hline Serum K & $4.61 \pm 0.37$ & $3.71 \pm 0.96$ & $4.29 \pm 0.99$ & 3.60 & \pm 0.48 & 1.002 & 0.319 \\
\hline CRP & $92.60 \pm 56.13$ & - & $215.09 \pm 74.584$ & & - & $6.238^{*}$ & $<0.001$ \\
\hline PCT & $0.027 \pm 0.015$ & - & $4.817 \pm 15.14$ & & - & $3.322 *$ & $<0.001$ \\
\hline Glycaemia & $0.19 \pm 0.89$ & - & $1.23 \pm 3.51$ & & - & $5.231 *$ & $<0.001$ \\
\hline
\end{tabular}

$\dagger$ - Mean \pm SD, F- Anova for repeated measurements, * - Mann-Whitney test

\section{Discussion}

In people aged 65 years and older, the risk of death to the patient from the required surgical procedures is three times higher than to the younger population, especially in the case of emergency conditions [1]. In our study none of the age groups represented significant risk factors in early postoperative mortality $(p=0.922)$. Emergency surgery is a well-known risk factor [4]. It increases the operative mortality rate from 3 to as many as 10 times [5]. We determined that emergency surgery was the significant risk factor of death outcome in our patients $(\mathrm{p}<0.001)$. Patients with higher ASA score have more chance of death outcome [6], as it was shown in our survey $(\mathrm{p}<0.001)$. The chronic diseases presence is tightly connected with death outcome [7]. Some studies indicate that the primary preoperative factor for a poor surgical outcome in the elderly was the comorbidity itself rather than age [8]. Respiratory and renal diseases were statistically significantly more common in deceased gastric surgical patients $(\mathrm{p}=0.003 ; \mathrm{p}<0.001)$. Our research showed that serum creatinine values were statistically significantly higher in deceased gastric surgical patients ( $p<0.001$ ), which was in correlation with other authors [9]. Hypoalbuminemia is a common laboratory abnormality in the elderly, which can lead to high morbidity and mortality [10]. Our research showed that hypoalbuminemia was independent risk factor of fatal outcome $(p=0.024)$ The serum hemoglobin concentration was higher in surviving gastric surgically treated patients, compared to the deceased ones, at the level of statistical significance, which was in correlation with previous studies [10]. In sepsis, the underlying problem is the high rate of mortality, which is even higher than in patients at the moment of myocardial infarction [11]. The incidence of sepsis is $2 \%$ of all hospitalizations, and 6-30\% in intensive care units [12]. We determined that the CRP and Le count values were statistically significantly higher in deceased gastric surgical patients $(\mathrm{p}<0.001)$, correlating with published data [10]. Anastomosis dehiscence leads to greater pain and distress of the patient than any other surgical complication [13]. Dehiscence of gastro-intestinal anastomosis was determined in 5 deceased gastric surgical patients, representing statistical significance risk factor of death outcome (Fisher's test: $p=0.002$ ). The surgical outcome of patients who need transfusion is poor, and it is not clear whether this is due to bleeding, anemia, or the transfusion itself [14]. In our study, surviving gastric surgical patients had less transmitted RBC concentrate units $(\mathrm{p}=0.025)$ and more transmitted FFP units $(\mathrm{p}=0.005)$.

\section{Conclusion}

Total mortality rate was $28.7 \%$. In gastric surgical patients, death outcome was more statistically common in: emergency surgical patients, patients with anastomosis dehiscence, respiratory and kidney comorbidities, higher ASA score patients and patients with higher serum values of creatinine, glycemia, CRP and PCT. Surviving gastric surgical patients had less transmitted counts of RBC concentrate units and more transmitted counts FFP units referring to deceased patients.

\section{References}

1. Richardson JD, Cocanour CS, Kern JA, Garrison RN, Kirton OC, Cofer JB et al. Perioperative risk assessment in elderly and high-risk patients. J Am Coll Surg 2004; 199(1):133-146.

2. Seymor DG. Gastrointestinal surgery in older age: issue of equality and quality. Gut 1997; 41:427-429.

3. Wolters U, Wolf T, Stützer H, Schröder T. ASA classification and perioperative variables as predictors of postoperative outcome. Br J Anaesth 1996; 77(2):217-222. 
4. Ingraham AM, Nathens AB, Peitzman A, Bode A, Dorlac G, Dorlac W et al. Assessment of emergency general surgery care based on formally developed quality indicators. Surgery 2017; 162: 397-407.

5. Havens JM, Peetz AB, Do WS, Cooper Z, Kelly E, Askari R et al. The excess morbidity and mortality of emergency general surgery. $\mathrm{J}$ Trauma Acute Care Surg 2015; 78:306-311.

6. Amrock LG, Neuman MD, Lin HM, Deiner S. Can routine preoperative data predict adverse outcomes in the elderly? Development and validation of a simple risk model incorporating a chart-derived frailty score. J Am Coll Surg 2014; 219(4): 684-694.

7. Ozturk E, Yilmazlar T. Factors affecting the mortality risk in elderly patients undergoing surgery. ANZJ Surg 2007; 77:156-159.

8. Wilson I, Barrett MP, Sinha A, Chan S. Predictors of in-hospital mortality amnong octogenarians undergoing emergency general surgery: A retrospective cohort study. Int J Surg 2014; $12: 1157-1161$.
9. Visser A, Geboers B, Gouma DJ, Goslings JC, Ubbink DT. Predictors of surgical complications: A systematic review. Surgery 2015; 158(1):58-65.

10. Horasan ES, Dag A, Ersoz G, Kaya A. Surgical site infections and mortality in elderly patients. Med Mal Infect 2013; 43(10):417-422.

11. Esper A, Martin GS. Is severe sepsis increasing in incidence and severity? Crit Care Med 2007; 35:1414-1415

12. Jawad I, Luksic I, Rafnsson SB. Assessing available information on the burden of sepsis: global estimates of incidence, prevalence and mortality. J Global Health 2012; 2:1-9.

13. Falconi M, Pederzoli P. The relevance of gastrointestinal fistulae in clinical practice: a review. Gut 2001; 49(Suppl IV): 2-10.

14. Kim Y, Spolverato G, Lucas DJ, Ejaz A, Xu L, Wagner D et al. Red cell transfusion triggers and postoperative outcomes after major surgery. J Gastrointest Surg 2015; 19:2062-2073. 